ARTICLE

DOI: $10.1057 /$ s41599-017-0025-0

\title{
Psychoneurosis beyond Oedipus: neurophysiology, drive conflict, and the resolution of emotional trauma
}

\author{
Cheryl A. Logan ${ }^{1}$
}

\begin{abstract}
The concept of plasticity infused regenerative approaches to brain science in Switzerland in the mid-twentieth century, shaping a holistic tradition prominent among Zurich's psychiatrists and neurologists. From 1910 to about 1950, they sought to objectify the dynamic unconscious using a psychobiological approach to mental pathology pioneered by the neuroanatomists August Forel and Constantin von Monakow. Little scholarship, however, has explored this tradition. Both Forel and Monakow influenced Rudolf Brun, a Zurich neurologist and ant expert, who championed parallels between biological conflicts measured in social insects and Sigmund Freud's drive energetics. Brun's concept of drive conflict integrated Richard Semon's theory of plastic heredity as "species memory" with a revision of Monakow to explain mental pathology in the brain. Through them, he proposed the neuropathology underlying Freud's "genuine" psychoneuroses: those caused by unconscious memories of traumatic experience. This paper uses primary historical sources from the Swiss scientific literature to demonstrate that (1) Brun combined Semon's plastic heredity, Cannon's physiology and Pavlov's conditional reflex to objectify Freud's dynamic unconscious; and (2) though he rejected Monakow's teleology, Brun's holistic mind-body approach owed much to Monakow's theory of emotions and pathology manifest in the brain. Brun elaborated Monakow's view that psychopathology occurs as unconscious drive conflicts produce neurotoxicity, enabling excess hormones to disrupt the brain's protective filtering system. Brun's ant experiments confirmed evolutionary "laws" governing drive conflict and framed the neuro-energetics underlying the resolution of repressed emotional trauma. Tests pitted conflicts between social drives and those serving self-interest. Through them, Brun extended moral conflict beyond the Oedipal domain of psychoanalysis to encompass conflicts in a biological hierarchy of drives. This drive-based account of conscience explored neural pathways reaching back from the cortex to the body, so enabling traumatic memories to generate psychoneuroses. Plasticity could then justify the use of psychotherapy to reverse these pathogenic connections. Brun's example demonstrates both the significance of Semon's theory of heredity for objective accounts of the unconscious mind in Central Europe and the hidden legacy of Monakow's neuroendocrine holism. Brun combined that legacy with objective evidence and Zurich's emphasis on plasticity to endorse-somewhat paradoxically-the reversal of psychoneuroses in the brain.
\end{abstract}

\footnotetext{
${ }^{1}$ University of North Carolina at Greensboro, PO Box 26170, Greensboro, NC 27402-6170, USA. Correspondence and requests for materials should be addressed to C.A.L. (email: calogan@uncg.edu)
} 


\section{Introduction}

everal sources in the history of modern neurophysiology suggest that the idea of neuroplasticity is a relatively recent concept (for example, Rees, 2016). This may be accurate in some settings; in others, however, the concept was present-even dominant-before the turn of the twentieth century (Bates and Bassiri, 2016). One rarely addressed case is the regenerative neurophysiology that held sway in Swiss brain science after the turn of the twentieth century. Plasticity dominated Zurich's Brain Anatomy Institute. And early in the century, the Institute's emphasis on plasticity was linked to the emerging science of endocrinology, itself proliferating at roughly the same historical moment.

The problems that became scientific endocrinology-a field focused on the "ductless" or endocrine glands, the secretory products of which directly enter blood circulation-emerged in the 1880s amid debates about processes of bodily rejuvenation (Stoff, 2004). Endocrinology's early techniques were crude. But with some clinical success and the first chemical synthesis of a hormone-adrenalin-in 1904, the new term "hormone" came to denote a group of natural chemicals of great therapeutic value (Stoff, 2013; Schlich, 1998; Borell, 1985, 1976). And by about 1910, the science of endocrinology was associated with two constructs that had an unusual impact on its eventual integration with the nervous system: plasticity and holism.

The first construct originated with clinical observations showing that pervasive disorders of the mind and body could be reversed rather quickly by the administration of organ extracts. As a result, the endocrine effects of "inner secretions" traveling via blood circulation were often perceived as more plastic than purely neural effects (Logan, 2017; Sengoopta, 2006; Schlich, 1998). In Zurich, the gradual elaboration of neuroendocrine processes sustained a strongly regenerative approach to brain disease in neurology and psychiatry that was based in historical notions of neuroplasticity. The second construct appealed to scientists who criticized reductionist or overly mechanistic approaches to brain and mind. Because the glands' purported chemicals could theoretically alter any system touched by circulating blood, hormones offered the possibility of a holistic integration of what often seemed distinct and disparate processes. ${ }^{1}$ Both constructs influenced Swiss brain science through the pioneering thinking of Constantin von Monakow-founder and director of Zurich's Brain Anatomy Institute.

Psychiatry and neurology in Zurich were closely connected before the turn of the century. Two key figures, Monakow and August Forel, conceived their approaches to neurology and psychopathology in terms of neuroplasticity. Indeed, Forel's emphasis on plasticity underlay his defense of the neuron doctrine (Sleigh, 2007): the idea that brain fibers are not anatomically fused, but separate cells-called "neurons"-acting on one another across tiny spaces. ${ }^{2}$ Forel directed Zurich's Burghölzli psychiatric clinic for almost 20 years. And alongside his neuroanatomy (Parent, 2003), he was arguably the world's premier myrmecologist. Even in ants, however, Forel invoked plasticity; there too, mind was "a material and curable individual entity (Sleigh, 2007, p 47)." Through his concept of "instinct", Monakow paired plasticity with a morally tinged holism. He viewed the brain as a series of networks intimately interconnected both within the nervous system and with the remainder of the body. And through Monakow, though often in quite different philosophical dress, plasticity and holism shaped the application of neurophysiology to Swiss explanations of psychopathology.

In what follows, I focus on Louis Rudolf Brun (1885-1969), a man who from his youth had been fascinated by ants. I use Brun's empirical synthesis to establish three historical dimensions of Zurich's unusually integrative community of neurologists and psychiatrists. First, several aimed to objectify the unconscious mind. Brun, Monakow's student, was one of the first scientists to attempt an experimental objectification of Sigmund Freud's view of the unconscious (see also Strick, 2015). Classical psychoanalysis was based in subjective analyses of repressed memories and their elaborate symbolism in human motives and dreams. Brun would place these concepts on a firmer footing by anchoring them in a language of engrams, reflexes, drives, and hormones. Second, Brun sought a deterministic alternative to the teleology in which Monakow had embedded neuroplasticity. For this, Brun turned to the Russian experimentalist Ivan Pavlov and to the German morphologist Richard Semon. Semon is best known for his debates with geneticists over the inheritance of acquired characteristics. I present an important, but underappreciated perspective on Semon-one that foregrounds his impact on the Swiss sciences of brain and mind. There, Brun and others used his theory to anchor the unconscious mind in brain research. ${ }^{3}$ Finally, I show how Brun drew on Monakow's holistic endocrine approach to link higher brain centers-the mid-brain and cortex - to processes governing other vital organs of the body.

Brun's approach elaborated a neurophysiological distinction between the processes of "instinct" and "drive". His inspiration for doing this came from Freud's psychoanalysis. In 1919, after resuming work in Monakow's Institute, Brun realized that the results of experiments he was conducting on ants closely paralleled key aspects of Freud's thinking. ${ }^{4}$ He knew of Freud's neurological career and respected "the developmental-biological attitude that had always also distinguished the later psychoanalytic works of the great scholar (Brun, 1936, p 200)." Expanding Freud's view of the energetics of physiological drives, Brun extended his accounts of psychoneurosis and conscience beyond the sexual frame of psychoanalysis to propose a physiological, but holistic explanation of the psychological causes of neuroses.

Forel had introduced Brun to the elder's view of plasticity-one heavily indebted to Semon. And under Forel's mentorship, Brun began a career that interwove animal experiments into a theory of the restorative plasticity of the physiological processes underlying psychoneuroses. But Monakow's teleological and neo-vitalist framework had made his discoveries less and less consistent with twentieth century advances in brain science. Brun would have to strip Monakow of his teleology and reframe his neurophysiology into a deterministic account of mind-body reciprocity that was consistent with the energetics of psychoanalysis. Josef Breuer and Sigmund Freud had famously asserted that hysterics "suffer from reminiscences (Breuer and Freud, 1925/1955)." Using Semon and his revision of Monakow's theory of instinct, Brun would undergird the assertion of psychogenic causation "from the standpoint of biology and physiology (Brun, 1926, p 161)".

It was a grand synthesis. But by the 1950s, Semon's theories had been discarded in much of the West, and Zurich psychiatry was no longer receptive to Freud. Brun's reliance on their union eventually undermined his account of how, in the brain, memories of traumatic moral conflict cause psychoneuroses.

\section{Monakow's teleological theory of instinct}

In the early 1880s, the Russian-Swiss neuroanatomist Constantin von Monakow built a private laboratory while he worked as the assistant administrator of an insane asylum (Wiesendanger, 2010, 2006). There, he made use of a new device, the microtome, to greatly expand the field of cellular neuroanatomy. ${ }^{5}$ In 1894, after his return to Zurich, Monakow's laboratory eventually became Zurich's Brain Anatomy Institute. Though well known as a committed holist and praised for his functional approach to 
neuroanatomy (Finger, Koehler, and Jagella, 2004) especially in the visual system, Monakow was a neo-vitalist (see Wolfe, 2014; Normandin and Wolfe, 2013; Harrington, 1996). He privileged neuroplasticity; but he draped it in a teleological philosophy that made his framework increasingly uncomfortable for his successors.

At the center of Monakow's neurophysiological integration of human action through "instinct" are the notions of "horme" and "hormeterien." Monakow viewed horme as a creative force that instills forward progression in all life-a "propulsive force of the living being with all its inherited potential possibilities [that] adapts itself to the most distant future (quoted in Goldstein, 1931, p 6)." He wrote: "Human life with its many functional regimes, its cycles and vital phases... can be understood biologically as a striving march of the giant protoplasm, humanity, after the greatest possible certainty, satisfaction, adjustment, and perfection... (1950, p 233)." Apparent even in individual cells, horme was "a cosmic evolutionary impulse" that served Monakow's "naturalization of morality (Harrington, 1996, p 92, p 94; see also Verplaetse, 2009)."

After World War I, Monakow (1922, 1921b) explained how "instinct" sustains this moral progression. The energetic force of horme enlivens and directs instincts that are triggered by hormones, natural bodily chemicals that also generate felt urges. These primitive urges-the forerunners of mature emotionsreach deeply into human ancestry to guide "the operations of thought (Monakow, 1921b, p 288)." An individual's sensory experience then shapes human emotional complexity through an instinctification process ("hormeterien") that begins before birth and continues through various stages; these include a mimicry stage, puberty, and mature sexuality. The sexual instincts play an important role, eventually giving rise to advanced stages of "noohormeterien", which are aroused by psychological change and which ultimately shape the intellectual and moral instincts (Monakow, 1921b, pp 280-284). Through each phase of instinctification, antagonistic struggles and "feeling currents" of "the biological-physiological world" pit the interests of an individual against the interests of groups. As they do so, these struggles gradually hone adult emotions, preferences and moral sensibilities. The various "compromises" resolving the struggles produce derivative instincts that render self-interest consistent with advanced morality and group progress. Monakow believed that profound individual happiness could result from these compromises; they instill joy in all and ensure the wellbeing of the community.

The entire process is guided by emotions that also embody deep history. Each lived instant represents a "complex mental agitation" in which re-lived ancestral emotions transition to the future, shifting the balance of life toward a greater unified harmony. Monakow stressed the special difficulties of localizing emotions in the brain. But he was confident that only a neurochemical approach would work. The representation of emotion in brain was "unthinkable" without considering "the reciprocal influence... of nerve cell systems and the endocrine glands" (all quotes 1950, pp 150-152). Hormones might even act selectively in the central nervous system to ensure or inhibit emotional reactions during the "arbitration" of conflicts. But when these processes fail, their prolonged dysfunction produces psychopathology.

Monakow's speculations on conscience and the biology of morality did not always rely on his pioneering neuroanatomy. But he made two points clear. First, emotions are triggered not in the brain, but in the body's peripheral nervous system. They originate in the autonomic nervous system as ancient instincts, which, via hormones, generate primitive feelings (Urgefühle) even before birth. Second, as individuals' lives unfold, emotions are integrated with stored sensory experience (cognitive memories) as well as with the "species memory" of long dead ancestors. These layers of humanity's ancestry could, therefore, haunt individuals in the present. Monakow's use of ancestral memory endorsed a version of the inheritance of acquired characteristics. This was the idea, associated with the French evolutionist Jean-Baptiste Lamarck and accepted by Charles Darwin (and many biologists before the 1890s), that individual experience can change heredity (see Gissis and Jablonka, 2011). It was also the basis of Monakow's and Freud's (see Slavet, 2008) assumptions that the motives driving human action reflect the power of unconscious ancestral memories.

\section{Beyond "horme": anxiety and the laws of drive conflict}

After neurological study in London, Rudolf Brun returned to Zurich to specialize in neurology with Monakow. At the same time, with Forel's help, he published his first ant research, and Forel remained his mentor until the elder's death in 1931. Forel was also a key figure in the international monist movement. Monism was a philosophical worldview based in science and derived from the German Darwinist Ernst Haeckel, Semon's major professor (Gliboff, 2012; Richards, 2008). That worldview proposed a unified materialist and evolutionary vision of science, mind, and morality that flourished before World War I and took many forms (Weir, 2012; Ziche, 2012). Most of them interpreted mind and brain as a single entity. And it was through Forel that Darwinism and monism structured Brun's replacement of horme as well as his assumptions about the philosophy underlying psychoanalysis.

Brun defined neuroses as functional diseases of the nervous system based in drives. And, though he acknowledged that patients could also suffer from hereditary predispositions to "constitutional" neuroses, his conceptual integration stressed the physiology of "true" psychoneuroses: those caused psychogenically. ${ }^{6}$ Neuroplasticity was most clearly manifest in these disorders; they were, therefore, where the potential for "prophylactic" therapeutic interventions was greatest. To explain how memory caused psychopathology, Brun relied on Semon's theory of two kinds of memory-a hereditary "species memory" and the familiar cognitive memory. With them, Brun would reframe Monakow's "vicious circle" of pathophysiology. In 1915, Monakow (1950, p 181) had proposed that repeated affronts to vital interests could produce recurring cycles of emotional agony and somatic dysfunction, leading to mental illness. Using Monakow's research on the blood-brain barrier-a set of microanatomical and chemical processes that protect the brain-Brun re-interpreted the vicious circle, replacing Monakow's approach with Semon's concept of the resolution of discord in memory (species and individual).

Because it was deterministic and energy based, Semon's theory enabled Brun to avoid Monakow's teleology and build an account of the causal status of psychogenesis. Combining Semon with a revised vicious circle, Brun could reframe a holistic link between somatic and psychic causes. Memories did cause emotional storms that alter the neurochemistry of the brain's filter; but plasticity rendered that vicious cycle reversible. In ways understood through Freud's conflict energetics, disturbed memory networks could be brought into harmony with current reality.

Instinct fixity vs. drive plasticity. Throughout his writing, Monakow had referred to the biological automatisms triggering action using the words "drive" and "instinct" interchangeably. He subsumed both under the umbrella of horme. Brun had explored these automatisms in ants and glimpsed their differences. His first task was to clarify the neural distinction between them, eliminating 
Monakow's confusion and replacing horme with a Darwinian conception of the difference between instincts and drives. ${ }^{7}$

The social insects were central to this distinction. For Brun and many others, these animals embodied Nature's perfect instincts (Rodgers, 2008; Sleigh, 2007). And with them, Brun clarified the difference using evolutionary comparisons that stressed neuroplasticity. He believed that the outcomes of insects' instincts are stored in each species' "heredity-memory [Erbgedächtnis] in the form of pre-trained chain-reaction like" mechanisms of the nervous system (1920, p 88). This accounted for the animals' "peculiar blind irresistible urge... to pursue... a once-initiated instinctive sequence to the end (Brun, 1920, p 101)." If access to an instinct's external object were withdrawn, thereby interrupting the sequence, sustained internal stimulation nonetheless produced a "deep general instinctive agitation [Unruhe] that lasts until a specific stimulus input is obtained (Brun, 1920, p 100)."

Hormones triggered both instincts and drives: They were the master impetus activating the "execution organ"-the brain (Brun, 1920, p 99). But, unlike in insects, in higher animals there was no pre-set neural pattern and no blind pursuit; rather, Brun argued, drives' objects are established by individual experience. So, though the drive dispositions of higher animals involve ancestral heredity, once activated, the neural apparatus underlying them is guided by input from the environment. Brun's concept of drive fulfillment used Semon's theory to explain the relationship between a drive's impetus in heredity-memory and its "realization". To be realized adaptively-especially when resolution involved conflicts among drives-ancestral memory must be integrated with memory based in recent individual experience.

Unconscious mnemic plasticity. Early in the 20th century, Richard Semon, a German morphologist, elaborated a highly debated theory of "organic reproduction". By 1910, it had become the most respected scientific account of the inheritance of acquired characteristics. The theory assumed that latent traces of the physical stimuli that activate sensory processes are stored and remain prominent even after the sensations end. Semon termed these traces "engrams" and described the processes involving them as "mnemic." In his 1904 book, Die Mneme, he proposed an account of the function of engram networks that defined both human cognitive memories and-this was the controversial part -those reflecting a species' ancestral experience (Logan, 2015; Gliboff, 2012; Schacter, 1982). Both kinds could exist either in latent or in activated form. And once reactivated during embryonic development, the two types of engrams were unified as they guided plastic processes of readjustment that adaptively reshape life-either in mature cognition or as the body's organs take form during the process of morphogenesis (Semon, 1904/ 1920).

Feedback was the key to this readjustment. Semon proposed that when ancestral and novel engrams are "discordant" with one another, bodily feedback eliminates incompatible engrams and eventually restores a balance. Semon termed that balance "homophony." And though the resulting harmony between the two sources often varied across species, as engrams re-establish homophony, they effectively regulate a self-balanced integration of novel traces of individual experience with the ancient experience of ancestors.

Brun applied these processes to brain development. He had often seen plastic changes in the development of behavior occurring during insect metamorphosis. And, because they involve drives, he believed the processes would be even more plastic when applied to brain development in higher animals. Brun didn't just borrow Semon's terminology; he made it the basis of resolving drive conflicts. It explained how, as brains take form, drive satisfaction results from the "homophonic" resolution of conflicts among drives. I argue that Semon's theoryelaborated in brain-solved two problems for Brun. ${ }^{8}$ First, because engrams originate in the energy underlying sensation and can remain latent, they provided Brun with a concept of the unconscious that was consistent with Freud's energetics, but had none of flavor of Monakow's teleology. Second, Semon's account of mnemic plasticity generated during discord gave Brun a model for neuroplastic regulation that replaced Monakow's "hormeterien". Instinctification indeed involved change; but it was change shaped by prior engram regulation. Brun applied both solutions to the discord that he believed common in the drive and emotional lives of higher animals and humanity.

Drives: emotional election and emotional memory. Brun proposed that when a drive is awakened by hormones, "strongly chronological layers of the relevant heredity engram complex (1920, p 93)" activate a neural orienting process. In this process, ancestral experience produces a bias for objects that can satisfy the drive. This explained how a hunger drive always initiates a search for food and not for objects of love or protection. Brun (1926) argued that emotion is the glue: Drive satisfaction is mediated by pleasure, which eventually shapes mature emotions. In the process, the drive acts as a kind of template that, throughout life, has an "elective effect" on the control of emotions. A successful (satisfying) object quest depends on a kind of mnemic matching process, in which "the energetic situation that is given in the external world (outer) corresponds to the hereditary-mnemic situation recorded in heredity-memory [ der Erbmneme] (or otherwise stated: [when] the real sensed object... corresponds to the hereditary engram complex of the primitive representation of the drive [the template]), then the relevant objects of sensation are immediately endowed with a positive lustaccented feeling quality." Through pleasure, drive realization reliably produces "a severe inclining desire for the object" (all quotes 1926, p 150), which is then preferred over others.

Explaining the psychogenic effects of emotional trauma on the brain, however, also required understanding the energetics of conflicted or blocked emotions. Again, Brun looked to Semon. For example, to describe the restlessness seen in worker bees that had lost their broods (blocking their instincts/drives), Brun wrote: "This typical... anxious restlessness after object loss during the realization phase of the drive represents... a complete analog to a nervous anxiety attack [in humans], except that neurotic anxiety is generally triggered through internal denial." In both, object loss reduced "only the external sources of stimulation of the ecphorized [activated] instinct complex; but its inner sources of stimulation, hormonal stimuli and mnemic activation,... continue to act with unabated force! (both quotes, Brun, 1926, p 163)."

Brun's matching process reframed Monakow's hypothesis of emotional election by uniting the engram complexes that shape drive realization with Semon's "homophonic" regulation. He had replaced Monakow's "compromises" with the resolution of discord in a plastic mnemic physiology that salvaged the elective role of emotions, while anchoring both processes in a deterministic energetics of sensation and its traces. Discord was the result of inevitable physiological tensions occurring among drives (Monakow's "struggles") and their corresponding emotions (his Urgefühle). And neuroplasticity restored emotional harmony between individual engrams and those in species memory in a process parallel to the one Semon had proposed for morphogenetic development. Engrams had provided a model of regulation that assured a return to balance. Summarizing his view of 
emotional election, Brun wrote: "[T]he positive or negative feeling-grades that we all attach to the objects of our world of experience... lie vested in our primary hereditary drive dispositions. They depend upon whether the particular outer energetic situation harmonizes homophonically or not with the particular hereditary-mnemic instinct stimulation (my stress, Brun, 1926, p 150)". "Ecphorized," "mnemic activation" and "homophonically" are Semon's terms; and with their logic, the latent energetics of anxiety began to make sense.

Morality and drive hierarchy. Brun's task was complicated by the fact that Freud and Monakow had proposed different theories of the nature of unconscious moral conflict. Surprisingly, Brun relied on Monakow's, not Freud's, view of morality to build a drive-based neurobiology, not a psychology, of conscience and its neurotic dysfunction. Uniting psychoanalysis with notions of neuroplasticity from Semon, he defended a regenerative therapeutic tradition that was undergirded by Monakow's approach to conscience.

Like Monakow's, Brun's approach would transcend sexuality and encompass all drives. To accomplish this, Brun proposed the distinction between primary and secondary drives. Primary drives demand immediate satisfaction, and they always serve the interests of the individual. Secondary drives, however, are oriented toward the future. They serve the future interests of the individual and-importantly for Brun-those of the social group. He assumed that secondary drives are the more recently evolved derivatives of primary drives. They "only occur in socially organized living beings, and therefore can also be termed 'social drives'." In humans, their realization is "predominantly mnemic" - that is, plastic: It depends on syntheses of the two kinds of engrams. So even in humans, evolved drives differed from the "sensed stimulus complexes (Brun, 1926, pp 148-149)" that comprised the cultural basis of Freud's ego ideal. For Brun, the processes were no longer residues of sensation; they had evolved into true biological drives.

As such, Brun's social drives assumed the function that Freud vested in culture: conscience. Especially in conflicts with primary drives, Brun wrote, "their emotional representation is conscience [Gewissen]." Citing Monakow, he defined conscience as "precisely the instance that, in cases of collision, advances 'the interests of the future, of the individual and the race,' thus the interests of the secondary drives (both quotes Brun, 1926, p 149)." As in Monakow's hormeterien, conflicts generated feelings of remorse that sustain an individual's moral concern for the group. So Freud's by then outdated use of the biogenetic law, ${ }^{9}$ which, Sulloway (1979, p 373) argues, was the "pre-supposition" on which Freud based the Oedipal conflict, was revised to incorporate any conflicting drives that pitted self-interest against the greater good of the group.

Ants, like many species of bees, termites and wasps, are called social insects because they live in large altruistic groups in which specialized 'workers' serve other group members. Still impressed by the insects' instinctive morality, Brun expanded conflict beyond Freud's Oedipal domain to emphasize such true social drives. In so doing, he ensured a secure biology of morality that rendered the Oedipal conflict only one of many pathogenic biological tensions. Stressing drive vs. drive, Brun could reject purely mechanistic accounts of mind and retain Monakow's social ethic, while instilling causality through the "chronological layers" of hereditary engrams by which he had eliminated horme. Disturbed memories were bathed in an endocrine blood chemistry of diverse moral conflicts that had reduced Oedipus to a special case-an important special case.
The "laws" of drive conflict. Nonetheless, Freud's account of neurotic drive conflict drew on two dimensions that Brun believed would be "extremely fruitful" for understanding mental dysfunction (Brun, 1926). They were the energetic and economic dimensions of Freud's metapsychology, seen through Semon's mnemic dynamics. ${ }^{10}$ Brun's revision of Monakow provided the physiology and expanded the morality; but the energy dynamics were still Freud's. To revisit the questions raised by Freud's energetics, Brun needed evidence; he obtained it from research on the conflicts he saw in social insects.

Brun developed the laws of drive conflict in experiments done on wood ants that pitted one instinct against another. Even as he praised Freud's genius, Brun (1926, p 154) wrote: Ants, "it needs hardly be said," are an "especially favorable" comparison. Their complex social instincts "permit recognition of numerous analogies with the situations of human drive life." Most important were conflicts between "the drives for self preservation and the social drives (1926, p 154)." Forel had already shown that when two primitive instincts-one social and one self-preservative-occurred simultaneously, the primitive social instinct (nest defense) prevailed. Brun then examined whether a phylogenetically older social instinct (nest defense) would dominate a phylogenetically younger one (altruistic brood care). He staged fights between ants from different nests that occurred when he introduced sacks holding one group near the nest of the other. When only the defensive instinct was active, lethal fights broke out. Then, before introducing the strangers, he gave the home group larvae and pupae, triggering brood care. Some fights occurred when he deposited foreign workers; but the brood's presence more often produced "an alliance (1926, p 155)" in which the unfamiliar and home ants cooperated to ensure the brood's safety. The conflict induced the "maximum of plasticity (adaptive ability)" (1926, p 154) of which ants were capable; and it confirmed the importance of phylogenetic history. Primitive drives were suppressed by more recently-evolved social drives. Because this pattern had also been observed in vertebrates and humans, Brun called it "the law' of the primacy of phylogenetically younger drives (1926, p 156)."11

Freud was especially significant for Brun's next question-the dynamics and economy of drive energy in the face of the persistent suppression of drive satisfaction. Using research by the British physiologist Charles Sherrington, Brun first summarized the results of "persistently inhibited drive stimulation" in simultaneously active incompatible reflexes mediated by the spinal cord. Sherrington had shown that "stimulation... was conserved..., it outlasted the inhibition and simply impinged [on motor neurons] later (Brun, 1926, pp 159-161)." Plus, an "afterdischarge" could produce a reflex of even greater intensity than had occurred before inhibition; and latent, accumulating energy sometimes even enabled an inhibited reflex to displace the reaction that had once inhibited it. Sherrington had measured these processes in the simplest of spinal reflexes; yet, Brun (1926, $\mathrm{p}$ 161) believed, they offered a "remarkable physiological parallel... [to] repression in human drive conflicts: a return of the repressed only in modified, that is, symbolic form."

To demonstrate these dynamics in complex behavior (and brain), Brun (1926) described experiments in which a drive's object was withdrawn while queen ants engaged in founding a colony. If the drive's realization phase were already underway, the sudden removal of eggs just laid provoked severe anxious restlessness (ängstliche Unruhe) - an agitated rushing about. Brun stressed that this wasn't 'real' anxiety. Nonetheless, he viewed the restlessness following loss of the social drive's object as "a complete analogue ( $\mathrm{p} 163$ )" of the anxiety attacks produced in neurotics by internal denial. Brun's argument moved back and forth between humans and social insects, acknowledging 
important differences. In both, however, the energy dynamics confirmed Freud: Inhibited drive energy was redirected via mnemic regression to phylogenetically older drives in which selfinterest prevailed over group wellbeing. Even in ants, "atavisms" and "regressions" reflected continued stimulation "in the form of a substitute output [which] regresses to an onto- or phylogenetically older [neural] tract (1926, p 165)." In humans, the neurotic anxiety triggered by blocking social and ethical drives yields "a curious anxious agitation that we describe as the remorse of conscience [Gewissensangst], and that, as concerns its mental (subjective) and bodily (objective) symptoms, makes no distinction between real and sexual anxiety (Brun, 1926, p 163)." In his zeal to confirm the dynamics of repression, Brun had grafted drive conflict onto Freud's emotional energetics to defend the origins of psychoneuroses in a biological morality. But how did it all play out in the brain?

\section{The psychogenesis of pathology}

"If instead of 'idea' we chose to speak of 'excitation of the cortex', the latter term would only have any meaning for us in so far as we recognize an old friend... and tacitly reinstated 'idea'. For while ideas are constant objects of our experience..., 'cortical excitations' are... rather in the nature of a postulate, objects which we hope to identify in the future."

This is Josef Breuer's introduction to his theoretical comments in Studies in Hysteria (Breuer and Freud, 1925/1955, p 185). By the 1930s, Brun believed that the future had arrived. Having used Semon to revise Monakow's concept of emotional election and built a hierarchy of drives that confirmed Freud's energetics, all that remained was to understand how conflicted traumatic emotions alter the central nervous system. Again, Brun turned to Monakow.

Monakow's "vicious circle". Beginning in 1918, Lina Stern, a physiological chemist trained in Geneva, published a series of studies on the fluid that circulates around the brain and through its ventricles. This fluid and several features of the brain's cellular anatomy form a barrier that protects the brain from some chemicals, while admitting others. (Wiesendanger, 2010; Vein, 2008). Stern described the fluid's chemistry and the direction of its flow - chemicals could get from the brain to the bloodstream, but not from the blood to the brain. In 1921, she introduced the modern term "blood-brain barrier" (Vein, 2008); and by the mid 1920s, there was good evidence that the fluid (the cerebrospinal fluid) circulated in a non-reversible direction through the brain's four ventricular cavities and into spaces surrounding the base of the spinal cord.

Monakow too, examined the blood-brain barrier (1921a). ${ }^{12} \mathrm{He}$ confirmed that the barrier's structure comprises several nonneural elements: the choroid plexuses on the walls and floors of the ventricles; the ependymal and sub-ependymal tissue; and several glial cells (Brun, 1954). ${ }^{13}$ His working hypothesis was that the "ventricular liquour", which is generated in the choroid plexuses, penetrates internally though brain areas and into open crevices, while "glial scaffolding [Gliagerüst]" ensures that the fluid even remains "in closest contact with brain tissue [Hirnparenchym]" (1921a, p 233, see Fig. 1). Used fluid carrying dissolved byproducts of metabolism ("Detritus") then flows away from the brain and drains out through the spinal cord.

The blood-brain barrier's protective filtering was the basis of Monakow's view that dysfunction in the physiology of emotion produces psychopathology. In 1919, he and his student Sidanichi
Kitabayashi, described the oddly pathological anatomy of the choroid plexuses and the membranes adjacent to ventricular cavities in the brains of schizophrenics. The findings supported Monakow's hypothesis that psychoses occur when disruption of its protective filtering system chronically poisons the brain (Wiesendanger, 2010; Brun, 1954; Kitabayashi, 1922). The barrier's protective function could break down; when it did, a toxic build up of substances could cause psychopathology.

Monakow stressed that this toxic build up would include natural hormones. A strong release of emotion could produce a pathological increase in hormones reaching the central nervous system. Under normal conditions, such an emotional "storm" would be balanced by counter-stimulation from the autonomic nervous system (ANS), which restored mental security. ${ }^{14}$ But with prolonged or persistent repetition of mental crises, recurring reactivation of the ANS would trigger more and more unresolved emotional collisions. The result was Monakow's "vicious circle" of neuroendocrine and emotional overstimulation, which produced "nervousness or neurosis". But such pathogenesis also must somehow involve memory; and Monakow acknowledged that empirically-even chemically_that possibility remained the "darkest puzzle (1950, p 158)."

Reigning dogs and cats. By the 1940s, Brun had applied several advances in endocrinology and neurophysiology to solve that puzzle. In greatly revised form, Monakow's "plexus theory" became a piece of the "reversible pathophysiological dysfunction" through which Brun explained the psychogenesis of neuroses. In the third edition of his comprehensive work on neuroses, General Theory of Neurosis (Allgemeine Neurosenlehre) (1951/1954), Brun critiqued and expanded the plexus theory. The book is a comprehensive account of the causes and treatments of all types of neuroses. In it, Brun reiterated his praise of Freud, the etiological centrality of hormones and drives, and the value of Semon for explaining how drive conflicts are resolved. Much was added to two earlier editions, the impact of which, Brun wrote, had been limited because they had appeared during or just after World War II. Scientists in the warring nations had been too busy to notice.

Brun assumed that the hormones that are especially important for understanding psychoneuroses are adrenalin and the sex hormones. He had good reasons. The American physiologist Walter Cannon had already discovered that in cats strong emotions could, via the hormones of the adrenal gland, stimulate the emergency ('flight/fright') branch of the autonomic nervous system (Dror, 2014, 1999). And Austrian reproductive physiologist Eugen Steinach had shown that young male rodents whose sex glands became atrophied could, after exposure to the odors of females, undergo a "secondary erotization" (Brun, 1954, p 60). Their glands once again secreted, reactivating the animals' sex drives (Logan, 2017). Brun interpreted both findings as evidence that endocrine glands could react to higher neurosensory input. Cannon had also demonstrated that when the two divisions of the ANS - the emergency flight/fright-inducing branch vs. the restorative branch-were triggered simultaneously, the emergency system (the "sympathetic") always prevails. Brun considered this finding to be fundamental for understanding psychoneuroses: It meant that the brain could aggravate a sense of emergency that was triggered peripherally and experienced as anxiety.

Monakow too had stressed the ANS. But the findings described above all indicated the importance of the central nervous system's involvement in emotions and control of the ANS. Integrating these findings, Brun proposed that mid-brain control areas that regulate the ANS send signals upward to alter the responsiveness of the cerebral cortex. They exercise "a kind of 'rheostat function' in relation to cortical activity.... The cortex therefore becomes in 


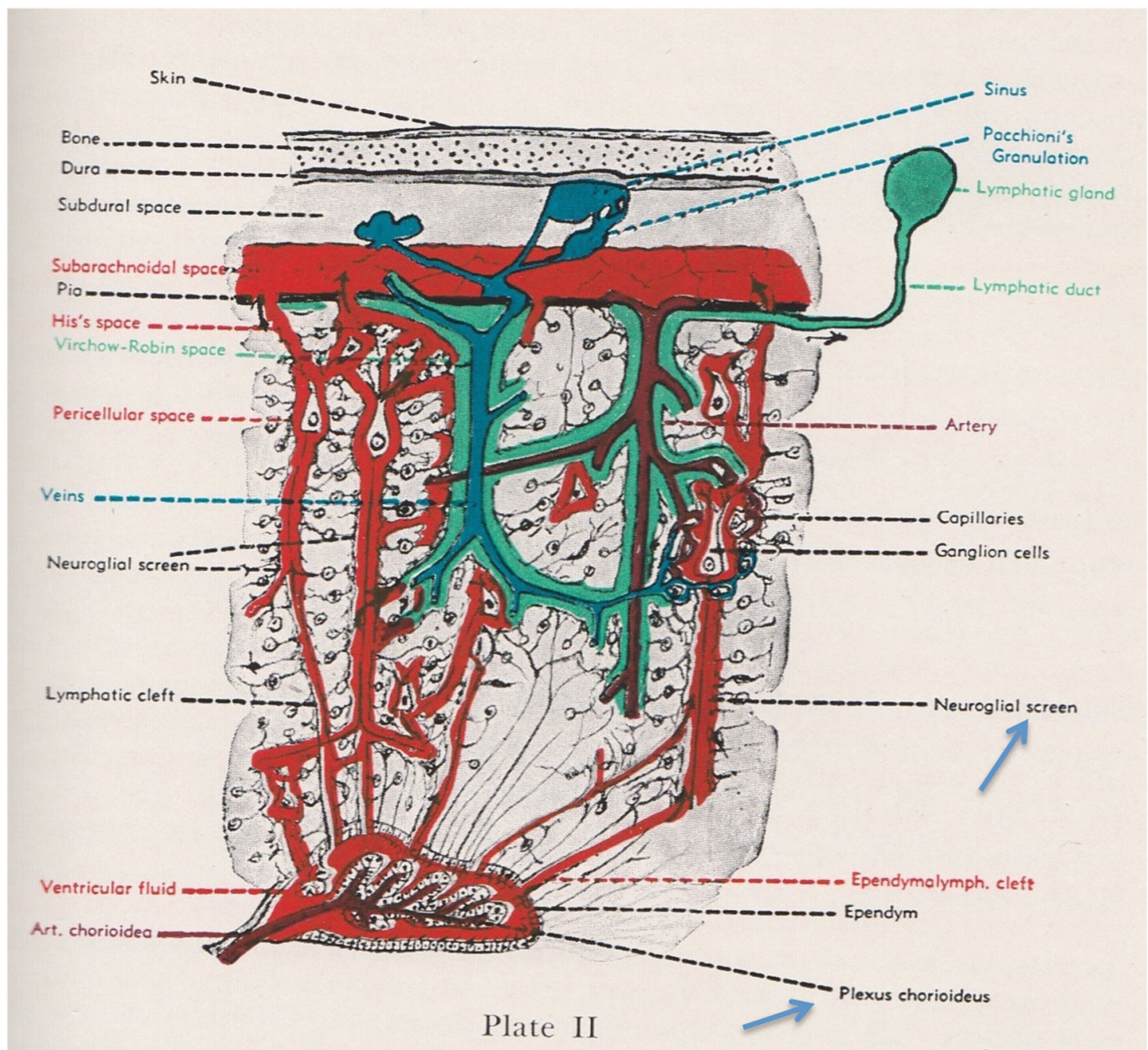

Fig. 1 Brun's rendering of Monakow's account of the internal circulation of the cerebrospinal fluid (in red/orange) that is produced in the choroid plexus (bottom arrow) and guided by a neuroglial screen (upper arrow), which moves the fluid upward through brain tissue (from Rudolf Brun, 1951/1954, General Theory of Neurosis/Allgemeine Neurosenlehre, 3rd German Edition). Reproduced with the permission of Schwabe AG Verlag, Basel

a certain sense a target organ of the mid-brain!" The sensory processes of the brain "[are] depending on the 'mood' of the midbrain, suddenly raised, suddenly subdued.... But all other basic mental powers of the cortex,... in short 'mental elasticity [Spannkraft],' is also extensively influenced by the relevant processes of the mid-brain." One could, Brun wrote, even speak straightforwardly of " mid-brain dementia' (all quotes 1954, p 15; Brun's italics)."

But establishing the reverse-neurophysiological psychogenesis - was complicated by the long-term complexity of psychoneuroses. Brun had already distinguished between the primary causes of neurosis and the secondary symptoms that often aggravate or prolong a problem. This was clear in clinical cases in which a primary glandular function was damaged by, for example, tumors. Even with the diagnosis of such a purely somatic cause, patients often experienced fear or depression that secondarily aggravated their symptoms. If they could aggravate, why couldn't psychic processes initiate a problem? Secondary mental complications suggested that "disturbances of the endocrine equilibrium need not necessarily be primary, but... may just as well be activated secondarily by the psyche (Brun, 1954, p 65)."

Other key discoveries helped untangle these complexities and clarify interactions between the mid-brain and cortex. The famed Russian physiologist Ivan Pavlov had shown that the "vegetative" reflexes of the autonomic nervous system in dogs could be transferred through simple association to otherwise indifferent events (those without inherent drive-related affect) (Todes, 2002, 2014). When this occurred, an indifferent stimulus could eventually, by itself, trigger an ANS reaction. Using this method, Pavlov's students had even shown that stimuli could be arranged so that the function of an autonomic reflex was suppressed. Sometimes "the animal falls into a state of [either] general excitement... or more or less complete inhibition (Brun, 1954, p 148-149)". Both Brun and Pavlov saw these states as analogous to human neuroses.

Brun believed that Pavlov's "associative reflexes" of the autonomic system had "suddenly brought our understanding of the vegetative symptoms of psychoneuroses, especially hysteria [and]... the many phobias" considerably closer. ${ }^{15}$ Autonomic reflexes could "at any time become secondary to conditional psychoreflexes." This extended the influence of the cortex to "nearly all the sub-cortical innervation processes" (all quotes, Brun, 1954, p 149), causally linking sensations and memories to drives and emotions. Despite their significance, however, Brun acknowledged that Pavlov's dogs could not explain the complexity of most human psychoneuroses. The conditional associations of animals were labile and short-lived; but in humans, psychoneuroses seemed to constantly increase in strength. Even when initiated by 
childhood taboos, internal inhibitions could pervade virtually all aspects of someone's life. To establish psychogenesis in humans, Brun believed, one must also explain how engram complexes become so entangled with unconscious perceptions and emotions that originate over broad spans of time. As I've argued, for Brun, this deep, historical influence came from Semon's heredity memory. And that concept's role in the disrupted processes of drive realization-the repression of drive conflict-was also key to Brun's revision of Monakow's vicious circle.

The vicious circle in "genuine" psychoneuroses. Freud had distinguished "actual neuroses" (neurasthenia, shock, and anxiety neuroses) from what Brun understood as the psychoneuroses proper (hysteria, phobias, and obsessional neuroses). Analyzing both in detail, Brun speculated that the two groups represented distinct forms of psychogenesis. Actual neuroses were like the neuroses of Pavlov's dogs. A psychoreflex simply evoked a physiological one, transferring the affect of the original unconditional reflex to memories of recent events (lodged in the cortex); thereafter, such memories exercised no more influence over the ANS. This resulted in a diffuse and "object-less" anxiety containing no "psychological content (1954, p 119)". The second group, however, represented psychogenesis in "the narrower sense". This involved a "complex conditionality wherein psychic processes of an unconscious kind not only trigger symptoms as conditional psychoreflexes, but also decisively collaborate in detail in the choice and the form of the symptoms (Brun, 1954, p 83)." The diffuse effects of a damaged blood-brain barrier triggered by Pavlovian conditioning could account for the former; but such non-specific poisoning could not explain the elaborate symptom formation seen in "genuine" psychoneuroses, the latter group. Their symptoms were specific and historically symbolic. But how was the arrow of causality reversed, enabling entangled engram networks to radiate from the cortex back to the mid-brain and initiate a weakening of the blood-brain barrier?

The solution came from two additional sources: Brun's countryman, Zurich physiologist Walter Hess, and his colleague Mieczyslaw Minkowski. ${ }^{16}$ Hess demonstrated that several primal emotions associated with activation of the ANS were represented in sub-thalamic areas of the mid-brain in cats. These were the areas "from which the vegetative reflexes radiate affective stimuli (Brun, 1954, p 74)." And, Brun noted, they are located near the ventricles that produce the cerebrospinal fluid. This could explain "why, with insufficiency (leakiness) in the blood-brain barrier, always whenever vegetative and affective disturbances prematurely erupt," toxins from the ventricles "express themselves first in periventricular nerve centers (both quotes, Brun, 1954, p 74)".

Minkowski provided the "anatomical proof" (Brun, 1954, p 143). Brun described Minkowski's lesion experiments, which were done on the cortices of primates. They showed the existence of connections traveling from the forebrain and motor cortex back to several mid-brain areas. Brun admitted that some of these connections synapsed via a second tract; but these too, reached the mid-brain. And together they "guaranteed the exertion of control by the cortex over the entire reflex apparatus (Brun, 1954, p 144)" of the mid-brain. Experimental findings from Pavlov's dogs and Hess's cats, along with Minkowski's "corticofugal" fibers, convinced Brun that engram complexes in the cortex were causally connected to downstream emotional storms that dysregulated the autonomic system. Freud had been on the right track: The energetics of suppressed/repressed and unresolved emotional conflicts could produce a "strangulation of affect" (Breuer and Freud's phrase), which, in Brun's analysis, could block homophonic regulation. Emotional storms could indeed yield a vicious circle in the brain. And sometimes those storms flowed corticofugally-from cortex to mid-brain and the ANS, to either initiate or aggravate increased "permeability" (1954, p 103) of the blood-brain barrier. "There is, therefore, in my opinion and from an anatomical standpoint no more reason to doubt the possibility of a purely psychogenic trigger of visceralnervous and hysterical phenomena" (Brun, 1954, p 144).

\section{Brun's biased monism: unpacking phobias}

Brun was involved in the Swiss psycho-hygiene movement, which was led by the German émigré psychoanalyst Heinrich Meng. The movement pioneered a prophylactic psychoanalytic pedagogy for children (Plänkers, 1996). ${ }^{17}$ Brun and Meng agreed on the importance of psycho-hygiene in stemming the increasing prevalence of neuroses in most "civilized countries". And, though many neurologists still denied that memories might cause neuroses, Brun's synthesis had placed the idea on an objective footing. His neuroanatomical account of reciprocal cortical connections was, he believed, "of the greatest significance for an explanation of the physiological mode of action of psychotherapy (1954, p 144)." Because it justified scientifically the value of psychotherapy for restoring the "elasticity" needed to heal, it was an important supplement to psycho-hygiene.

Brun considered true psychoneuroses to be organic in the trivial sense that they are disruptions of normal interactions among brain cells. For years, he had seen their "elasticity" in action, as he used psychotherapy to reverse his patients' psychoneuroses. He devoted large sections of General Theory of Neuroses to clinical accounts of the three major psychoneuroses that he believed could cause prolonged neuroendocrine dysfunction. I illustrate his approach with what he considered the simplest of the three: phobias. How did he apply his theory of physiological psychogenesis to the etiology of phobias?

Young Max. Brun, like Freud, distinguished general anxiety neurosis from phobia. In true psychoneurotic phobia, anxiety was not general; it was triggered by emotional traumas that were vested in specific objects. ${ }^{18}$ In the process, Brun assumed, the ego develops anxiety about its own inner drive state. That anxiety signals "drive danger [Triebgefahr]": the primary source of phobic anxiety. Eventually, however, "[t]here accrues to the purely physiological-hormonal moment of libido choke a second psychological factor..., which confers a special coloring not only to psychoneurotic anxiety, but also extensively co-determines further processes that are fastened to the primary process of drive anxiety [Triebangst] (Brun, 1954, p 369, last italics mine).

Brun used the case of a young boy, whom he called Max, to illustrate. When Max was about twelve, Brun treated him for a complex web of phobias that included fears of gymnastics and taking school examinations, as well as fears of nighttime burglaries occurring only while he was in bed, of fire, of automobile collisions (unless he sat in the front seat with his father), of sausages, of bridges, and of mortal damage that might befall his father, especially during rail travel. During analysis, Brun traced the origin of these phobias to a sexual trauma that Max had experienced at age ten.

A strange man had accosted him in a forest, initiating oral sex on Max, while exposing his erect penis. The phobias and their related rituals resulted from castration anxiety linked to this episode and to Max's fear of physically attaining masculine virility. This, guilt at masturbation and jealousy toward his father (triggered when Max was very young and saw his parents having sex) were at the root of all his problems. Castration complex, reaction formation, repression, regression and the postponement of gratification via a cathected substitute-all were invoked in Brun's analysis of the etiology of Max's phobias. 
In only one way did Brun's elaborate theory of cortical psychogenesis inform his clinical assessment. His description of Max's treatment interpreted the associative processes involved as manifestations of conditional reflexes, which had co-determined hormonal and tangled mnemic processes. The later bodily symptoms accompanying Max's phobias (heart palpitations, shortness of breath, vomiting, etc.) were not endocrine in origin; they were consequences of specific episodes in which anxiety had become conditioned to "particular objects that represent repressed objects or situations in consciousness.... In no other psychoneurosis do we see the release of symptoms by the mechanism of the conditional reflex so clearly... as in phobias (Brun, 1954, p 379)." Yet, the fear nonetheless had its origin in the "primary process of drive anxiety" and the objects accompanying it. Brun had reversed himself on what was primary and what secondary.

There was a contradiction embedded in Brun's solution. He had borrowed the chemistry of personal trauma from Cannon's emergency physiology. Either as a primary endocrine cause or as the secondary consequence of secretions conditioned by entangled memories, psychoneurotic anxiety required an outpouring of adrenalin. For Brun, anxiety was adrenalin. His theory of phobia mentioned co-determination; yet he also described the anxiety generated by drive danger as primary. Was adrenalin primary or was Max's Oedipal conflict? Could a truly psychogenic psychoneurosis be triggered by drive-evoked adrenalin? Clinically, Brun had interpreted Max's anxiety in terms of sexual conflicts that symbolized Oedipal and sexual fear. Phobic anxiety, he wrote, is "no longer released merely hormonally" - no longer simply a "quantitative energy transformation (Brun, 1954, p 369)". It is unclear how short the "physiological-hormonal moment" was that Brun described in the quote above; and he was silent on any boundary separating 'normal' drive danger from its pathological form. But, notwithstanding his elaborate speculations on biological morality, drive danger and the energetics of conflict potentially involving many drives, on the couch Brun reverted to sexual symbols-mental events-as the triggers of psychoneurosis. He seems to have wanted it both ways.

Agglutinated causality. The source of the contradiction-invisible to Brun-was likely Brun's acceptance of Monakow's concept of "agglutinated causality". In much of his book, Brun supported his explanations of psychogenesis in psychoneuroses using a consistent physiological objectivism, illustrated by his equation of anxiety and adrenalin. In a debate with a psychiatrist over the concept of utility, Brun (1934, p 159-160) denied that an organism could ever be viewed as an active source of change. Considered via natural science, organisms change "purely passively". Even in pathology, phenomena are "as a matter of principle, based in the same natural laws as the so-called normal". Hormones dictated his natural laws of emotion. So adrenalin could tell Brun objectively that anxiety was real. That objectivism - paradoxical for a committed monist for whom mind and body were one-had freed Brun from Monakow's teleology. But Monakow also left Brun with a bias against the use of subjective concepts in scientific explanation, a bias linked to his account of agglutinated causality.

Monakow too, recognized similarities between his theories and Freud's. But he was critical of Freud's work (and of all "scientific" psychology). He considered Freud's theory "ambilogical”- "part human, part biological”, because it inappropriately combined the language of psychology with that of biology (Monakow, 1929, p 79). The basis for his critique was agglutinated causality, Monakow's philosophical argument about the distorted character of causation as perceived subjectively. The concept led him to reject all psychological language as too imprecise for any truly scientific account of mind or mental illness (Monakow, 1922, 1929). That precision had to come from physiology and morphogenesis. So, though he praised parts of Freud's theory, the problem of agglutinated causality made the guided introspection of psychoanalysis too compacted and distorted to reflect true causes. Its language-originally, Monakow disdained, the "language of poets"-could never untangle the deep history of bodily collisions that reveals the nature of emotions and the origin of their conflicts.

Brun accepted Monakow's view of agglutinated causality. In nature, causes could reach to latent ancestral hereditary engrams. I suggest that Brun's biased monism enabled him to champion psychogenesis in the therapeutic setting only after he had conceptualized it integrating endocrinology, neurotoxicity and the cortex. It would not have been sufficient to have used only his patients' ideas, memories, and feelings. But Brun had more. Scientifically, he had consistently used the "chronological layers" of Semon's species heredity to explain these processes. Through a revised vicious circle, which integrated Pavlov, Hess, Cannon and Minkowski, those layers had yielded an "objective" cortical synthesis that Brun assumed underlay conflicts, repressed memories and their therapeutic release. Linked to cortical engrams transmitted back to the ANS, that synthesis justified psychogenesis and psychotherapy scientifically, freeing Brun from the burden of any mistakes inherent in Freud's "ambilogical" language. Having physiologized the processes, then, in the clinic, Brun could comfortably trust the subjective language of Freud's concepts. There was no contradiction, because he knew what those concepts really meant.

Freud scholar Frank Makari (2008) notes that psychoanalysis was popular in Europe partly because it offered an alternative to the therapeutic nihilism and degenerationism that had plagued early psychiatry. Given his emphasis on prophylaxis, this advantage probably also influenced Brun's reliance on Freud. $\mathrm{He}$ had expanded the function of hormones to include regulatory influences coordinating an anatomically distributed and hormonally driven vegetative system informed by Semon's mneme theory and Freud's energetics. With their union grafted onto a revised "vicious circle", his account of psychogenesis refuted neurologists who had assumed that conditions like hysteria were purely organic, and so could not be treated. Of course they were organic; so was psychogenesis. Those neurologists had mistakenly ignored the "causal-developmental explanation (Brun, 1954, p 140)" of symptoms associated with a reciprocal network of drives, neurochemical influences and emotion-laden conditional engrams. By not combining all, they had failed to see the temporal depth and the reversibility of brain micro-trauma. Their rigid views of the organic flew in the face of the Zurich tradition of neuroplasticity, which Brun had inherited from endocrinology, Monakow and Semon, and which his biased monism could take for granted.

Received: 22 June 2017 Accepted: 12 October 2017

Published online: 07 November 2017

\section{Notes}

1 Endocrine discoveries in Switzerland in the late nineteenth century had already established the value of these constructs. Theodor Kocher's thyroid interventions transformed the understanding of cretinism, a disorder common in the Alps that affected mind and body. Thyroid extracts quickly restored children to health, and Kocher became a cultural hero-the first Swiss citizen to win a Nobel Prize in the sciences (Schlich, 1998, 1994).

2 Now called synapses, these spaces, which disrupt signal conduction between neurons, became the basis of modern neurophysiology (see Guillery, 2005). Freud too, 
proposed them in his "Project for a Scientific Psychology" (see Gamwell and Solms, 2006, p 103).

3 The renowned Zurich psychiatrist Eugen Bleuler was among them (see Möller and Hell, 1999).

4 In 1925, Brun opened a private practice in neurology; he completed a training analysis for psychoanalytic practice in 1926 and taught regularly at the Brain Institute (Aeschlimann, 1980).

5 The microtome was a recently invented device for cutting very thin slices of the brain that could then be color-stained and described in greater detail under a microscope.

6 Freud did not invent the concept of psychoneurosis. Brun attributed it to Charles Paul Dubois, a Swiss neuropathologist, who in 1905 published Die Psychoneurose und Ihre Behandlung (The Psychoneuroses and Their Treatment).

7 Perhaps influenced by his Russian origins, Monakow rejected Darwinism; see Todes (1989) on the Russian evolutionary tradition.

8 Forel was in frequent correspondence with Semon, who at the time vigorously debated geneticists over the inheritance of acquired characteristics. Forel became one of Semon's greatest defenders; and when Brun first met Forel, the older man advised him to explore Semon's theories (Aeschlimann, 1980). Richard Semon committed suicide in 1918.

9 The nineteenth century hypothesis that the embryonic development of an individual repeats in stages the phylogeny of the species.

10 Brun equated Freud's term "metapsychology" with "biopsychology (Brun, 1926, p 148)." I use "metapsychology" in Patricia Kitcher's (1992) sense: The dynamic, topographic, and economic dimensions of mind introduced by Freud, and which defined the approach to theory construction that shaped his synthesis.

11 When describing his experiments, Brun too, used the terms "drive" and "instinct" interchangeably because he assumed that the energetics underlying his laws were the same for plastic drives, more rigid instincts, and the symbolism of human drives. Animal experiments, however, also showed that there were exceptions to the laws.

12 Stern used dyes to demonstrate the fluid's circulation, while Monakow charted its microanatomy, origin and flow. Stern, by 1920 one of the few women with a professorial chair in Europe, left Geneva in 1925 for her native Russia. In 1939, she became the first woman elected to the Russian Academy of Sciences. She was imprisoned by the Soviets during Stalin's purge of Jewish scientists (see Vein, 2008).

13 The ependyma is the cellular lining of the brain's ventricles and the second membrane separating the brain from the skull. Monakow's hypothesis included a lymphatic route of circulation that could help remove metabolic byproducts that were suspended in the cerebrospinal fluid.

14 The autonomic nervous system consists of several nerve ganglia positioned vertically in the brainstem and along the spinal cord. They coordinate the actions of vital organs, such as the heart, lungs, stomach and glands, with the brain. Walter Cannon's research on control by the adrenal gland of the two divisions of the autonomic system, one activating and the other restorative, was well known in Switzerland (on Cannon see Dror, 2014)

15 By 1920, Monakow, Brun and Semon had each drawn parallels between Semon's theory and Pavlov's research. On Pavlov's acceptance of the inheritance of acquired characteristics, see Todes (2014).

16 Minkowski was Brun's contemporary. In 1928, he succeeded Monakow as director of Zurich's Brain Anatomy Institute.

17 Meng, also a monist, eventually became Director of the Institute for Psychohygiene in Basel, Switzerland. He accepted Brun's synthesis as the neurological underpinning of psycho-hygiene.

18 Brun noted that general anxiety neurosis or any actual neurosis could be aggravated by the addition of a secondary psychoneurosis.

\section{References}

Aeschlimann J (1980) Rudolf Brun (1885-1969): Leben und Werk des Zürcher Neurologen, Psychoanalytikers und Entomologen. Juris Druck \& Verlag, Zurich

Bates D, Bassiri N (eds) (2016) Plasticity and pathology. On the formation of the neural subject. Fordham University Press, New York

Borell M (1976) Organotherapy, British physiology, and discovery of the internal secretions. J Hist Biol 9:235-268

Borell M (1985) Organotherapy and the emergence of reproductive endocrinology. J Hist Biol 18:1-30

Breuer J, Freud S (1925/1955) Studies on Hysteria (James and Alix Stracheytranslation). Basic Books, New York

Brun R (1920) Das Instinktproblem im Lichte der modernen Biologie. Schweizer Archiv fürNeurologie und Psychiatrie 6:80-124

Brun R (1926) Experimentelle Beiträge zur Dynamik und Ökonomie des Triebkonflikts (Biologische Parallelen zu Freuds Trieblehre). Imago. Zeitschrift für Anwendung der Psychoanalyse auf die Geisteswissenschaften 12:147-170

Brun R (1934) Eugen Bleuler: Mechanismus-Vitalismus-Mnemismus. Schweizer Archiv für Neurologie und Psychiatrie 34:155-162

Brun R (1936) Sigmund Freuds Leistungen auf dem Gebiete der organischen Neurologie. Schweizer Archiv für Neurologie und Psychiatrie 36:200-206
Brun R (1954) Allgemeine Neurosenlehre. Biologie, Psychoanalyse und Psychohygiene leib-seelischer Störungen, 3rd edn. Benno Schwabe, Basel, (English edition, 1951, General Theory of Neuroses. International Universities Press: New York.)

Dror OE (1999) The affect of experiment: The turn to emotions in AngloAmerican physiology, 1900-1940. Isis 90(2):205-237

Dror OE (2014) The Cannon-Bard thalamic theory of emotions: A brief genealogy and reappraisal. Emotion Rev 6:13-20

Finger S, Koehler PJ, Jagella C (2004) The Monakow concept of diaschisis. Origins and perspectives. Arch Neurol 61:283-288

Forel A (1910) Gehirn und Seele. Alfred Kröner Verlag, Leipzig

Gamwell L, Solms M (2006) From neurology to psychoanalysis. Sigmund Freud's neurological drawings and diagrams of the mind. SUNY Binghamton, Binghamton NY

Geroulanos S, Meyers T (2016) Integrations, vigilance, catastrophe: The neuropsychiatry of aphagia in Henry Head and Kurt Goldstein. In: Bates D, Bassiri N (eds) Plasticity and pathology. On the formation of the neural subject. Fordham University Press, New York, p 112-158

Gissis S, Jablonka E (2011) Transformations of Lamarckism: from subtle fluids to molecular biology. MIT Press, Cambridge, MA

Gliboff S (2012) Monism and morphology at the turn of the twentieth century. In: Weir T (ed) Monism: Science, Philosophy, Religion, and the History of a Worldview. Palgrave, New York, p 135-158

Goldstein K (1931) Konstantin von Monakow. Deutsche Zeitschrift für Nervenheilkunde 120:1-7

Guillery RW (2005) Observations of synaptic structures: origins of the neuron doctrine and its current status. Philos Trans Royal Soc London B Biol Sci 360 (1458):1281-1307. https://doi.org/10.1098/rstb.2003.1459

Harrington A (1996) Reenchanted Science. Holism in German Culture from Wilhelm II to Hitler. Princeton University Press, Princeton NJ

Kitabayashi S (1922) The choroid plexuses in organic disease of the brain and in schizophrenia. J Nerv Ment Dis 56:21-26. Critical review by M Minkowski

Kitcher P (1992) Freud's Dream. A Complete Interdisciplinary Science of Mind. MIT Press, Cambridge MA

Logan C (2015) Engrams and biological regulation: What was 'wrong' with organic memory? Memory Stud 8(4):407-421

Logan C (2017) The physiology of erotization: Comparative neuroendocrinology in Steinach's Physiology Department. In: Müller G (ed) Vivarium. Experimental, Quantitative, and Theoretical Biology at Vienna's Biologische Versuchsanstalt. MIT Press, Cambridge MA, p 209-230

Makari G (2008) Revolution in mind. The creation of psychoanalysis. Harper Collins, New York

Möller A, Hell D (1999) Das allgemeinpsychologische Konzept im Spätwerk Eugen Bleulers. Fortschritte der Neurologie Psychiatrie 67:147-154

Monakow C (1950) Gefühl, Gesittung und Gehirn. In: Gehirn and Gewissen. Psychobiologische Aufsätze. Morgarten Verlag, Conzett and Huber: Zurich

Monakow C (1921a) Der Kreislauf des Liquor cerebro-spinalis. Schweizer Archiv für Neurologie und Psychiatrie 8:233-234

Monakow C (1921b) Versuch einer Biologie der Instinktwelt. Schweizer Archiv für Neurologie und Psychiatrie 8:257-292

Monakow C (1922) Versuch einer Biologie der Instinktwelt. Schweizer Archiv für Neurologie und Psychiatrie 10:240-274

Monakow C (1929) Zur Krisis der Psychanalyse. Schweizer Archiv für Neurologie und Psychiatrie 24:75-99 and 333-347

Monakow C, Kitabayashi S (1919) Schizophrenie und Plexus chorioidei. Schweizer Archiv für Neurologie und Psychiatrie 4:363-365

Normandin S, Wolfe CT (eds) (2013) Vitalism and the scientific image in postenlightenment life science: 1800-2010. Springer, Dordrecht

Parent A (2003) Auguste Henri Forel (1848-1931). J Neurol 250:635-636

Plänkers T (1996) Idee und Wirklichkeit einer Psychohygiene. Biographie und Werk Heinrich Mengs (1887-1972). In: Kretz H (ed) Lebendige Psychohygiene. Eberhard, Munich, p 17-41

Rees T (2016) Plastic reason. An anthropology of brain science in embryogenetic terms. University of California Press, Berkeley

Richards R (2008) The tragic sense of life. Ernst Haeckel and the struggle over evolutionary thought. University of Chicago Press, Chicago

Rodgers DM (2008) Debugging the link between social theory and social insects. Louisiana State University Press, Baton Rouge LA

Schacter D (1982) Stranger behind the engram. Theories of memory and the psychology of science. Erhlbaum, Hillsdale, NJ

Schlich T (1994) Changing disease identities: Cretinism, politics and surgery (1844-1892). Med Hist 38:421-443

Schlich T (1998) Die Erfindung der Organtransplantation. Erfolg und Scheitern des chirurgischen Organersatzes (1880-1930). Campus Verlag, Frankfurt am Main

Semon R (1904/1920) Die Mneme als erhaltendes Prinzip im Wechsel des organischen Geschehens. Engelmann, Leipzig

Sengoopta C (2006) The most secret quintessence of life. Sex, glands, and hormones: 1850-1950. University of Chicago Press, Chicago 
Slavet E (2008) Freud's 'Lamarckism' and the politics of racial science. J Hist Biol 41:37-80

Sleigh C (2007) Six legs better. A cultural history of myrmecology. Johns Hopkins University Press, Baltimore

Steinberg DA (2009) Cerebral localization in the nineteenth century-The birth of a science and its modern consequences. J History Neurosci 18(3):254-261. https://doi.org/10.1080/09647040802025326

Stoff H (2004) Ewige Jugend. Konzepte der Verjüngung vom späten 19. Jahrhundert bis ins Dritte Reich. Böhlau Verlag, Köln

Stoff H (2013) Vital regulators of efficiency: the German concept of Wirkstoffe, 1900-1950. In: Schwerin A, Stoff H, Wahrig B (eds) Biologics. A history of agents made from living organisms in the twentieth century. Pickering \& Chatto, London, p 89-104

Strick JE (2015) Wilhelm Reich. Biologist. Harvard University Press, Cambridge MA

Sulloway F (1979) Freud. Biologist of the mind. Basic Books, New York

Todes D (1989) Darwin without Malthus: The struggle for existence in Russian evolutionary thought. Oxford University Press, Oxford

Todes D (2002) Pavlov's physiology factory. Experiment, interpretation, laboratory enterprise. The Johns Hopkins Press, Baltimore

Todes D (2014) Ivan Pavlov. A Russian life in science. Oxford University Press, Oxford

Verplaetse J (2009) Localizing the moral sense: Neuroscience and the search for the cerebral seat of morality, 1800-1930. Springer, Dordrecht, London: New York

Vein A (2008) Science and fate: Lina Stern (1878-1968), a neurophysiologist and biochemist. J Hist Neurosci 17:195-206

Weir T (ed) (2012) Monism: Science, philosophy, religion, and the history of a worldview. Palgrave Macmillan, London

Wiesendanger M (2006) Constantin von Monakow (1853-1930): A pioneer in interdisciplinary brain research and a humanist. C R Biol 329:406-418

Wiesendanger M (2010) Constantin von Monakow (1853-1930) and Lina Stern (1878-1968). Early explorations of the plexus choroideus and the blood-brain barrier. Schweizer Archiv für Neurologie und Psychiatrie 161(4):140-144

Wolfe CT (2014) The organism as ontological go-between: Hybridity, boundaries and degrees of reality in its conceptual history. Stud History Phil Sci Part C 48:151-161

Ziche P (2012) Monist philosophy of science: between worldview and scientific meta-reflection. In: Weir T (ed) Monism: Science, philosophy, religion, and the history of a worldview. Palgrave Macmillan, London, p 159-177

\section{Acknowledgements}

I am very grateful for conversations with and comments from several colleagues, including Todd Preuss, Timothy Johnston, and Sharon Salinger. Discussions with Phillip Honenberger provided especially valuable input during the early stages of the project.

\section{Data availability}

Data sharing is not applicable to this article because no quantitative datasets were generated or analyzed to produce the current study.

\section{Additional information}

Competing interests: The author declares no competing financial interests.

Reprints and permission information is available online at http://www.nature.com/ reprints

Publisher's note: Springer Nature remains neutral with regard to jurisdictional claims in published maps and institutional affiliations.

\section{(c) (i)}

Open Access This article is licensed under a Creative Commons Attribution 4.0 International License, which permits use, sharing, adaptation, distribution and reproduction in any medium or format, as long as you give appropriate credit to the original author(s) and the source, provide a link to the Creative Commons license, and indicate if changes were made. The images or other third party material in this article are included in the article's Creative Commons license, unless indicated otherwise in a credit line to the material. If material is not included in the article's Creative Commons license and your intended use is not permitted by statutory regulation or exceeds the permitted use, you will need to obtain permission directly from the copyright holder. To view a copy of this license, visit http://creativecommons.org/ licenses/by/4.0/

(C) The Author(s) 2017 